\title{
An Empirical Study on the Relations between Rural Energy Consumption and Economic Growth
}

\author{
Qiu Chen \\ College of Economics and Management, Sichuan Agricultural University \\ 211 Hui Min Street, Chengdu 611130, China \\ E-mail:canyuenongxue_2006@163.com \\ Lin Zhang (Corresponding author) \\ College of Economics and Management, Sichuan Agricultural University \\ 211 Hui Min Street, Chengdu 611130, China \\ E-mail: zhanglin2762@126.com \\ Yuansheng Jiang \\ College of Economics and Management, Sichuan Agricultural University \\ 211 Hui Min Street, Chengdu 611130, China \\ E-mail: yjiang15@yahoo.com.cn
}

$\begin{array}{lrr}\text { Received: May 10, } 2011 & \text { Accepted: June 26, } 2011 \quad \text { Published: October 1, } 2011 \\ \text { doi:10.5539/ass.v7n10p86 } & \text { URL: http:/dx.doi.org/10.5539/ass.v7n10p86 }\end{array}$

\begin{abstract}
By using the granger causality test and impulse response function, this paper analyzed the causal, dynamic and quantitative relations between rural energy consumption and economic growth on the basis of the data from 1980 to 2007 in China, and then drawn a conclusion that rural economic growth is the granger cause of rural energy consumption with a lag of 5 years; rural economic growth has a direct influence on the rural energy consumption. Its contribution is gradually increasing year by year, and it has already reached $22.117 \%$ at period 10 . Based on this conclusion, this paper considered that the new point of rural economy should be explored; the construction of rural energy should be strengthened; the energy conservation awareness of farmers should be promoted; and the structure of rural energy consumption should be changed.
\end{abstract}

Keywords: Rural energy consumption, Economic growth, Granger causality test, Impulse response function, Variance decomposition

\section{Introduction}

As energy consumption increased rapidly along with the economic growth in China, the relevant data shows that China has already been the world's second-largest energy consumer. China's economy has been increasing year by year, but the energy reserves are limited, how to eliminate the obstacles between energy shortage and economic growth has become a key work for national economy presently. The Chinese government has promulgated "Central No.1 document" to pay close attention to "Three Rural Issues" for 7 consecutive years since 2003, regarding rural economic development, new countryside construction and agricultural modernization as emphasis in work all along. Moreover, "low carbon economy", as a popular topic, was repeatedly discussed at the APEC Summit in 2007, the meeting of NPC and CPPCC in 2008 and the Copenhagen Climate Summit in 2009. At present, it is of great importance to vigorously develop the economic mode based on low energy consumption, low-pollution and low-emission, increase the rate of rural energy utilization, adjust the structure of energy consumption, and spread innovative energy technology as well as emission reduction technology.

Corresponding to the rapid development of farming, forestry, animal husbandry and fishery, close relationship between rural economic growth and rural energy consumption has been established. It is necessary to do the 
further research on the relations between rural energy consumption and rural economic growth, in order to achieve the goal that rural economic growth and realization of low carbon economy. An accurate judgment of the relationship between them can help government departments to formulate and implement relevant policies, optimizing the consumption structure of rural energy, improving rural energy utilization, propelling innovation of energy technology. Therefore, to do empirical analysis of the relations between rural energy consumption and rural economic growth have practical significance and theoretical value.

\section{Literature review}

Foreign scholars had done extensive empirical studies on the relationship between energy consumption and economic growth. Kraft.J and Kraft.A (1978) used annual data of the USA in their pioneering study to analyze the relation between GDP and energy consumption, and they found unidirectional causality from GDP to energy consumption. Yu and Choi (1985) verified one-way causality from energy consumption to economic output in the Philippines, however the direction of the causality is opposite in Korea. Erol and Yu (1987) completed an empirical research based on the data from England and other six Industrializing Countries, and the results demonstrated that bidirectional causality between GDP and energy consumption exists in Japan, while the causality between energy consumption and GDP in Canada, England, France, Italy and Germany is in one direction. Soytas (2003) discovered bidirectional causality in Argentina, and unidirectional causality from GDP to energy consumption in Italy and Korea, from energy consumption to GDP in France, Germany, Japan and Turkey. Abdulnesser and Manuchehr (2005) proposed that energy consumption makes no difference to GDP, but GDP can effect energy consumption, there exists causality from energy price to energy consumption and GDP in Sweden.

A majority of domestic scholars had done many empirical studies on the relations between energy consumption and economic growth from the national level. Ma H.W. and Zhang Z.T. (2005) used grey correlated analysis to analyze the relations between them. He H. (2006) adopted threshold regression to analyze the quantitative relations in nationwide. Zhao J.W. and Fan J.T. (2007) firstly used nonlinear STR model to analyze the structure compliance relations between energy consumption and economic growth in china, and they draw a conclusion that the influence of economic growth to energy consumption had nonlinear, unsymmetrical and obvious stage characteristics. Wang H.G. and Shen L.S. (2008) established a tri-element production function model by introducing energy consumption into original production function based on the data from 30 provinces in china, and they found that energy consumption is the cause of economic growth. Zhou J.Q. and He Z.Z.(2009) used VECM to do an empirical study on the relations between energy consumption and economic growth on the basis of the data from 1953 to 2007, from demand and supply perspectives, they drawn a conclusion that long-term equilibrium relationship and bidirectional causality exist between GDP and energy consumption. Guo J. and Zhang L. (2008) also conducted an empirical study on the relationship between these two indicators by using multivariable cointegration test based on VECM model, the results showed that there is a long-term equilibrium relations among GDP, labor force, capital stock and energy consumption, and energy consumption is an unidirectional cause of GDP in short-term. Ma Y.X. (2008) discovered one-way causality from economic growth to energy consumption, and the short-term influence of economic growth on energy consumption is greater than that in long-term.

Furthermore, some scholars had also done many empirical studies on the relations between energy consumption and economic growth in some provinces of china. Yang G.Q. (2006) and Xie S. and Liu Q.H. (2007) found that there is a long-term equilibrium relationship between energy consumption and economic growth in Shandong Province and Guizhou Province, and it is a unidirectional causality from economic growth to energy consumption. On the contrary, Ren D.P. (2007) and Wang Z.F. (2008) proved that energy consumption is the unidirectional causality of economic growth in Xinjiang Autonomous Region. Xiong Y. (2008) supported the point of view that the growth of GDP and population could increase the amount of energy consumption. Zhang C.G. and Chen W.j. (2008) found that there is causality from energy consumption to economic growth in one direction in Guangdong Province, and slight fluctuation in energy consumption can make great influence on economic growth, and economic growth depends on energy consumption. Zhang Q. (2008) stated that long-term equilibrium relationship exists between energy consumption and economic growth in Anhui Province by establishing a extensional C-D production function model.

In conclusion, there are three kinds of causality relationships between economic growth and energy consumption: no causality, bidirectional causality or unidirectional causality. However, most of the existed literatures analyzed the relations from the macroscopic point of view, only a few literatures analyzed the relations from the angle of one industry. Therefore, this paper established a VAR model, and used granger causality test, impulse response function and variance decomposition methods to study the causalities, dynamic and quantitative relations between rural energy consumption and rural economic growth. 


\section{Data}

\subsection{Selection of indicators}

Based on the availability and authority of the data, this paper chose energy consumption in agriculture, forestry, animal husbandry, fishery and water conservancy industry as the indicator measuring rural energy consumption, all the data were selected from China Energy Statistic Yearbook and China Statistic Yearbook of each year from 1980 to 2007; The indicator measuring rural economic growth is Gross Output Value of Farming, Forestry, Animal Husbandry and Fishery, and the data were chosen from China Rural Statistic Yearbook.

\subsection{Descriptive analysis of sample data}

In the first place, this paper analyzed the change trend of the two variables in Figure 1.It can be clearly seen that the change of rural energy consumption and rural economic growth between 1980 and 2007 are not stationary but still in an upward trend. After 2000, the RGDP and REC both experienced significant increase.

\section{Empirical study}

\subsection{Granger causality test}

The most popular method adopted to judge causality relationships among time series is Granger Causality Test. However, as the non-stationary time series may cause spurious causality, then it is indispensable to do unit root test and co-integration test before taking the granger causality test.

\subsubsection{Stationary test}

\section{A. Methodology}

This paper chose ADF test to complete the unit root test. The ADF test states whether the time series are stationary or not, can be expressed as three models as follow:

$$
\begin{aligned}
& \Delta Y_{t}=\delta Y_{t-1}+\sum_{i=1}^{m} \beta_{i} \Delta X_{t-i}+\varepsilon_{t} \\
& \Delta Y_{t}=\alpha+\delta Y_{t-1}+\sum_{i=1}^{m} \beta_{i} \Delta X_{t-i}+\varepsilon_{t} \\
& \Delta Y_{t}=\alpha+\beta t+\delta Y_{t-1}+\sum_{i=1}^{m} \beta_{i} \Delta X_{t-i}+\varepsilon_{t}
\end{aligned}
$$

Where $\alpha$ is constant term; $\mathrm{t}$ is trend variable; and $\varepsilon_{t}$ is stochastic disturbance term.

There are hypothesis to test series

$$
\begin{aligned}
& H_{0}: \delta=0, \text { namely } \mathrm{Yt} \text { is non-stationary } \\
& H_{1}: \delta<0, \text { namely } \mathrm{Yt} \text { is not non-stationary }
\end{aligned}
$$

$\mathrm{ADF}$ is a regress test using each series own lagged terms with big differences. If calculated t-statistic value of variable is greater than ADF test critical t-value then $H_{0}$ can not be rejected and thus the data is non-stationary.

\section{B. Results of ADF test}

In order to improve the stability of all the time series and to unify the measurement unit of the variables, this paper obtains the natural logarithm of all the time-series data and makes unit root test by ADF test. All the results of the test are shown in table 1 .

It can be seen from table 1 that the level and the $1^{\text {st }}$-order difference of $\ln$ REC are both not stationary, while the $2^{\text {nd }}$-order difference of $\ln$ REC is stationary at $1 \%$ level of significant. The time series of ln RGDP is as the same. Therefore, these time series are I(2), and it can be further tested the cointegration relationship between two variables.

\subsubsection{Co-integration test}

\section{A. Methodology}

Time series RGDP and REC are both I(2), so EG test can be used to test the cointegration relationship between them. Specifically, the steps of EG test are in the following.

Firstly, set up a model including $\ln$ REC and ln RGDP as (4). 


$$
\operatorname{LnRGDP_{t}}=\alpha_{0}+\alpha_{1} \operatorname{LnREC}_{t}+\mu_{t}
$$

Use the OLS to estimate the model (4) and get the residual series $e_{t}$.

Secondly, take unit root test for $e_{t}$. In REC and $\ln$ RGDP are $(1,1)$ co-integration if $e_{t}$ is I(0); and ln REC and $\ln$ RGDP are $(2,1)$ co-integration if $e_{t}$ is I(1), and so on.

B. The results of EG co-integration test

The number of lags of model (4) is 1, and the co-integration vectors contain constant term. The results are listed in table 2 and table 3 .

As is shown in Table2, the trace statistic illustrated that there is a co-integration relationship between the variables in the model (4) at 5\% significance level, and the co-integration equation is $\ln$ REC $=0.45$ ln RGDP- 39 . This It can be indicated from the equation that there is a long-term equilibrium relationship between two variables from 1980 to 2007, and rural economic growth has positive influence on rural energy consumption.

\subsubsection{Granger causality test}

\section{A. Methodology}

After taking logarithm of rural energy consumption (REC) and rural GDP (RGDP), two binary linear equations can be acquired as follow:

$$
\begin{aligned}
& \ln \operatorname{REC}_{t}=\mathrm{a}_{0}+\mathrm{a}_{1} \ln \mathrm{REC}_{t-1}+\ldots \ldots+\mathrm{a}_{k} \ln \mathrm{REC}_{t-k}+\beta_{1} \ln \mathrm{RGDP}_{t-1}+\ldots \ldots+\beta_{k} \ln \operatorname{RGDP}_{t-k} \\
& \ln \mathrm{RGDP}_{t}=\mathrm{a}_{0}+\mathrm{a}_{1} \ln \operatorname{RGDP}_{t-1}+\ldots \ldots+\mathrm{a}_{k} \ln \mathrm{RGDP}_{t-k}+\beta_{1} \ln \mathrm{REC}_{t-1}+\ldots \ldots+\beta_{k} \operatorname{lnREC}_{t-k}
\end{aligned}
$$

$\mathrm{k}$ is the largest lags, and the null hypothesis is that the $\ln \mathrm{RGDP}(\ln \mathrm{REC})$ does not the granger cause $\ln \mathrm{REC}(\ln$ RGDP), namely: $\beta_{1}+\beta_{2}=\ldots=\beta_{k}$.

The granger causality test is based on the controlled F-statistic, the equation (5) can be took as an example.

$$
F=\frac{\left(R S S_{R}-R S S_{U}\right) / m}{R S S_{U} /(n-k)}
$$

where, $\mathrm{n}$ is sample size, $\mathrm{m}$ is the number of lags of $\ln \mathrm{REC}$ or $\ln \mathrm{RGDP}, \mathrm{k}$ is the number of all the unknown parameter in the equation. $\mathrm{RSS}_{\mathrm{R}}$ and $\mathrm{RSS}_{\mathrm{U}}$ are residual sum of squares. If $\mathrm{F}>\mathrm{F}_{\alpha}(\mathrm{m}, \mathrm{n}-\mathrm{k})$, the null hypothesis is rejected, and then it can be said that REC is the granger causality of RGDP.

B. The results of granger causality test

This paper took granger causality test to find the further relationship after getting the co-integration relationships between them. The test result can be seen in table 4(at 10\% significance level).

It can be seen from table 4 that the change of rural energy consumption is incapable of promoting the development of rural economy. On the contrary, the change of rural economic growth can cause the change of rural energy consumption. The number of the lags is 5 on average. Therefore, this paper considered that rural economic growth is the granger cause of rural energy consumption in one direction.

\subsection{Impulse response and variance decomposition analysis}

\subsubsection{Model}

Impulse response function can measure the influence trajectory by recording normal impact of random disturbance term on each variable in the system, and it can also portray the dynamic interplay and effect of the variables intuitively. In order to do impulse response analysis, this paper set up a VAR dynamic econometric model in the following:

$$
\begin{aligned}
& \ln \mathrm{REC}_{t}=\mathrm{a}_{11} \ln \operatorname{REC}_{t-1}+\mathrm{a}_{12} \ln \mathrm{RGDP}_{t-1}+\mu_{1, t} \\
& \ln \mathrm{RGDP}_{t}=\mathrm{a}_{21} \ln \mathrm{REC}_{t-1}+\mathrm{a}_{22} \ln \operatorname{RGDP}_{t-1}+\mu_{2, t}
\end{aligned}
$$

Finally, a dynamic model can be formed by combining the above two functions. An external disturbance can affect ln REC in function (7), then affect ln RGDP in function (8), and the interior transmission mechanism in these two functions could impact ln RGDP persistently.

\subsubsection{The results analysis}

In order to do a dynamic analysis of the impact of rural economic growth on rural energy consumption, it is necessary to analysis the impulse response of rural energy consumption to rural economic growth by the impulse response function based on the foregoing VAR model, the result can be seen in figure 2 . 
The horizontal axis in figure2 stands for lags of impact; The vertical axis stands for the response of ln REC; The full line means the ln REC's impulse response to ln RGDP; The dotted line means value of plus-minus twice standard error, and the forecast period is 10 years.

The figure 2 shows that $\ln$ RGDP has a positive impact on $\ln$ REC starting with the $1^{\text {st }}$ period after a positive stimulation being brought to it, and the effect increases constantly as time goes by. It is shown that rural economic growth can affect rural energy consumption continuously when external influence events happened. The deviation zone of plus-minus twice standard error experienced a increase, this means that the response error of ln REC caused by the impact of ln RGDP rises constantly over the time..

In order to make a quantitative analysis of influence on rural energy consumption from rural economic growth, this paper made variance decomposition for S.E. of $\ln$ REC in the established VAR model. Table 5 is the proportion change of the contribution of $\ln$ REC and ln RGDP to S.E. of $\ln$ REC from period 1 to 10.

The results demonstrate that the contribution proportion of rural economic growth in our nation to the change of energy consumption presents increasing trend during the observed period, and it will rise to $27.11 \%$ already at time point 10 . Thus, this can prove the analysis results of the impulse response function from a point of quantitative view. However, the values of standard error of In REC manifest that the estimated reliability of this model decreases with the time.

\section{Conclusions}

Based on the results of the analysis above, this paper can infer that the change of rural economic growth is a granger cause of the change of rural energy consumption in china, but rural energy consumption does not granger cause rural economic growth. What's more, rural economic growth can bring about positive influence that can be increased as time goes by on rural energy consumption. Slight fluctuation in the process of rural economic growth can make a significant influence on rural energy consumption. On the quantitative side, it turns out that the contribution of RGDP to the change of REC increases quickly year by year, and it will rise up to $27.11 \%$ at time point 10 .

The conclusions above can provide some important policy implications to the sustained growth of rural economic and the sustainable development of energy consumption as follow:

First of all, it is vital to explore new growth point for rural economy to promote persistent and stable development of the rural economy. Specially, the government should change the pattern of rural economic growth actively, cultivate the pillar industries which could stimulate rural economic growth, and guild them to develop in the direction of low energy consumption with high value-added.

What's more, the key work done for the sustainable development of energy by local government must be increasing the fiscal funds supporting the exploitation and construction of rural new energy. On one hand, local government has to take measures to popularize the using of biogas in rural areas. Not only can the measures reduce the consumption of coal and electricity, but also can they help rural households dispose animal waste, sewage, and so on. On the other hand, rural solar energy is a kind of new energy still remained to be exploited. Because most of the rural households live scattered, and the floor of their buildings is not very high that allows plenty of sunshine to their buildings, it is feasible to promote solar energy in rural areas. Finally, the hydropower in the countryside will deserve the further exploitation and utilization. Local government should support the construction of some small hydropower stations, canals for irrigation and many other facilities.

Last but not the least, the government should improve people's awareness of energy-saving and emission-reducing in rural areas in order to change the consumption structure fundamentally. Because the price of rural energy is low in a long run in our country, the people's awareness of energy-saving in the countryside remains long-term scarcity Therefore, the relevant government department should greatly propagate the guiding ideology of energy-saving, speed up the construction course of conservation-oriented society, raise the price of existing energy appropriately, and guild rural households to change their energy consumption habit as well as to exploit and construct new energy. Furthermore, it is necessary to develop rural energy technology vigorously to manufacture low energy-consumption products, and to improve the utilization rates of rural energy.

\section{References}

Abdulnasser, H. and Manuchehr, I. (2005). Energy Consumption and Economic Growth in Sweden: A leveraged Bootstrap Approach, (1965-2000). International Journal of Applied Economics and Quantitative Studies, No. 2, 87-98.

Asafu-Adjaye, J. (2000). The Relationship between Energy Consumption, Energy Prices and Economic Growth: 
Time Series Evidence from Asian Developing Countries. Energy Economics, No. 22, 615-625. http://dx.doi.org/10.1016/S0140-9883(00)00050-5

Erol, U. and Yu, E.S.H. (1997). On the Causal Relationship between Energy and Income for Industrializing Countries. Journal of Energy and Development, No. 13, 113-122.

Granger C W J. (1969). Investigating Causal Relations by Econometric Models and Cross-spectral Methods. Econometrica, No. 37.

Guo, J. and Zhang, L. (2008). An Empirical Study on the Relations between Energy Consumption and Economic Growth. Liaoning Project Technology University Journal (Social Sciences), (In Chinese), No. 3, 248-251.

He, H. (2008). An Empirical Study on the Variation Relations between Energy Consumption and Economic Growth: Based on Quantile Regression, Fujian province. Xiamen University.

Kraft J. and Kraft A. (1978). On the Relationship between Energy and GNP. Energy Development, No. 3.

Ma, H.W. and Zhang, Z.T. (2005). The Grey Correlation Analysis of Energy Consumption and Economic Growth. Market Weekly, (In Chinese), No. 5, 46-47.

Ma, Y.X. (2008). An Empirical Study on the Relations between Energy Consumption and Economic Growth. Neimenggu Agricultural University Journal (Social Sciences), (In Chinese), No. 5, 74-75, 84.

MacKinnon, J.G. (1996). Numerical Distribution Functions for Unit Root and Cointegration Tests. Journal of Applied Econometrics, $\quad$ No. $\quad$ 601-618. http://dx.doi.org/10.1002/(SICI)1099-1255(199611)11:6<601::AID-JAE417>3.0.CO;2-T

Ren, D.P. and Ai, M.H. (2007). An Empirical Study on the Relations between Energy Consumption and Economic Growth in Shandong Province. Commercial Times, (In Chinese), No. 29, 103-104.

Soytas, U. and Sari, R. (2003). Energy Consumption and GDP: Causality Relationship in G-7 Countries and Emerging markets. Energy Economics, No. 25, 33-37. http://dx.doi.org/10.1016/S0140-9883(02)00009-9

Wang, H.G. and Shen, L.S. (2008). A Study on Economic Growth and Energy Consumption: An Empirical Test Based on the Panel Data of 30 Provinces. Statistics and Decision, (In Chinese), No. 3, 125-128.

Wang, Z.F. et al. (2008). An Empirical Study on the Relations between Energy Consumption and Economic Growth in Xinjiang Province. Resource and Industry, (In Chinese), No. 12, 33-36.

Xie, S. and Liu, Q. H. (2007). Energy Consumption and Economic Growth in Guizhou Province. Guizhou Social Sciences, (In Chinese), No. 12, 92-96.

Yang, G.Q. (2006). Economic Growth and Energy Consumption: A nEmpirical Evidence from Shandong Province, Economic Management, (In Chinese), No. 11, 84-91.

Yang, X. (2008). An Empirical Study on the Relations between Energy Consumption and Economic Growth in Guizhou Province. Chinese Business Circles, (In Chinese), No. 11, 120-121.

Zhang, C.G. and Chen, W.J. (2008). An Empirical Study on the Relations between Energy Consumption and Economic Growth in Guangdong Province. International Economy Preliminary, (In Chinese), No. 6, 29-33.

Zhang, Q. (2008). Energy Consumption and Economic Growth: An Empirical Study of Anhui Province. Consume Guide, (In Chinese), No. 8, 51.

Zhao, J.W. and Fan, J.T. (2007). An Empirical Study on the Internal Compliance Relations between Economic Growth and Energy Consumption. Economic Study, (In Chinese), No. 8, 31-42.

Zhou, J.Q. and He, Z.Z. (2009). The Causality of Energy Consumption and Economic Growth: An Empirical Study from Demand and Supply Visual Angle. Industrial Technology Economics, (In Chinese), No. 11, 78-81. 
Table 1. The result of unit root test

\begin{tabular}{ccccc}
\hline Variable & test form(I/T/L & t-Statistic & Critical values (1\%level) & Prob.* $^{*}$ \\
\hline $\ln$ REC & $(\mathrm{I}, \mathrm{T}, 0)$ & -2.0521 & -4.3393 & 0.5479 \\
D(ln REC,1) & $(\mathrm{I}, 0,0)$ & -2.6538 & -3.7115 & 0.0821 \\
D(ln REC,2) & $(0,0,0)$ & -8.7277 & -2.6607 & 0.0000 \\
$\ln$ RGDP & $(\mathrm{I}, \mathrm{T}, 1)$ & -2.0014 & -4.3561 & 0.5734 \\
D(ln RGDP,1) & $(\mathrm{I}, 0,0)$ & -2.7257 & -3.7115 & 0.0833 \\
D(ln RGDP,2) & $(0,0,0)$ & -4.7049 & -2.6607 & 0.0000 \\
\hline
\end{tabular}

1. $\mathrm{D}(\ln \mathrm{REC}, 1)$ is $1^{\text {st }}$-order difference of $\ln \mathrm{REC}, \mathrm{D}(\ln \mathrm{REC}, 2)$ is the $2^{\text {nd }}$-order difference of $\ln \mathrm{REC} ; 2$. $(\mathrm{I} / \mathrm{T} / \mathrm{L})$ means variable's intercept, trend and lags.

Table 2. The cointegration test result

\begin{tabular}{ccccc}
\hline $\begin{array}{c}\text { Hypothesized No } \\
\text { of } \mathrm{CE}(\mathrm{S})\end{array}$ & Eigenvalue & $\begin{array}{c}\text { Trace } \\
\text { Statistic }\end{array}$ & $\begin{array}{c}0.05 \\
\text { Critical Value }\end{array}$ & Prob.* \\
\hline None & 0.244251 & 11.08226 & 20.26184 & 0.5342 \\
At most & 0.136011 & 3.801069 & 9.164546 & 0.4425 \\
\hline
\end{tabular}

Table 3. The ADF test result of residual series $e_{t}$

\begin{tabular}{llll}
\hline & & T-Statistic & Prob. $^{*}$ \\
\hline Augmented Dickey-Fuller test statistic & -5.867889 & 0.0003 \\
Test critical values & $1 \% \quad$ level & -4.374307 & \\
\hline
\end{tabular}

Table 4. The result of granger causality test

\begin{tabular}{cccc}
\hline Null Hypothesis & Obs & F-Statistic & Prob. \\
\hline & 27 & 0.5814 & 0.4532 \\
ln REC does not Granger Cause $\ln$ & 26 & 0.0539 & 0.9477 \\
RGDP & 25 & 0.0315 & 0.9922 \\
& 24 & 0.0203 & 0.9991 \\
& 23 & 0.0199 & 0.9998 \\
\hline ln RGDP does not Granger Cause $\ln$ & 27 & 3.7569 & 0.0644 \\
REC & 26 & 1.9941 & 0.1611 \\
& 25 & 1.5124 & 0.2453 \\
& 24 & 1.5431 & 0.2403 \\
& 23 & 2.9846 & 0.0560 \\
\hline
\end{tabular}


Table 5. The variance decomposition of $\ln$ REC from period 1 to $10(\%)$

\begin{tabular}{ccccccccccc}
\hline Period & 1 & 2 & 3 & 4 & 5 & 6 & 7 & 8 & 9 & 10 \\
\hline S.E. & 0.075 & 0.093 & 0.107 & 0.117 & 0.126 & 0.133 & 0.140 & 0.145 & 0.150 & 0.155 \\
$\ln$ REC & 100.00 & 97.407 & 94.220 & 90.785 & 87.406 & 84.160 & 81.080 & 78.173 & 75.441 & 72.883 \\
$\ln$ RGDP & 0.000 & 2.593 & 5.780 & 9.215 & 12.594 & 15.840 & 18.92 & 21.827 & 24.559 & 27.117 \\
\hline
\end{tabular}

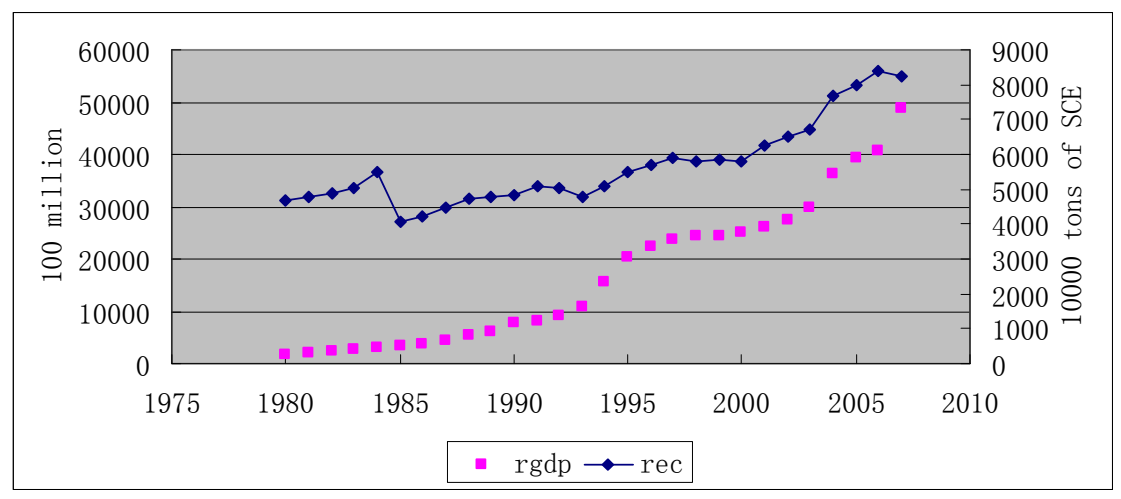

Figure 1. The Scatter Plot of Variables

The RGDP refers to "Rural Gross Output Value of Farming, Forestry, Animal Husbandry and Fishery", and the REC represents "Rural Energy Consumption".

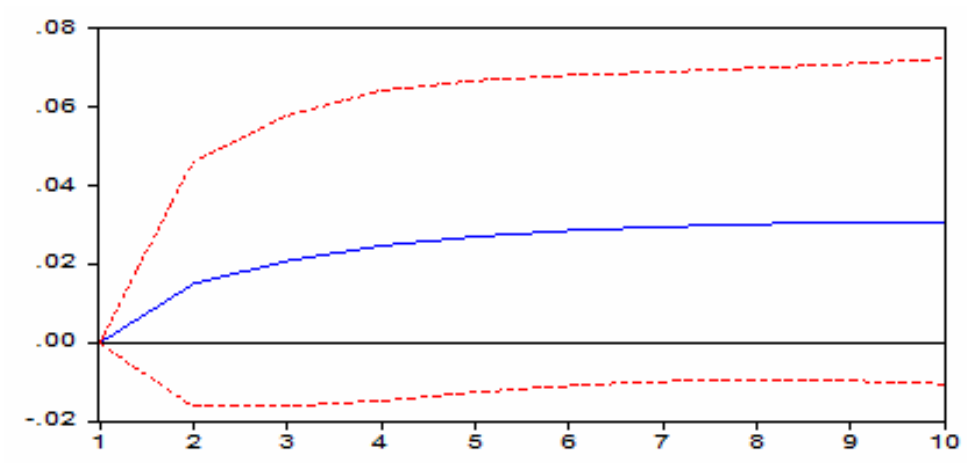

Figure 2. Response of $\ln$ REC to one S.D. of $\ln$ RGDP 